\title{
Electrochemical Determination of the Real Area of Nanocrystalline Boron Doped Diamond
}

Eduardo Saito, Fernando A. Souza, Adriana F. Azevedo, Neidenei G. Ferreira and Mauricio R. Baldan

ECS Trans. 2012, Volume 43, Issue 1, Pages 169-176.

doi: $10.1149 / 1.4704954$

Email alerting

Receive free email alerts when new articles cite this article - sign up in the service box at the top right corner of the article or click here

To subscribe to ECS Transactions go to: http://ecst.ecsdl.org/subscriptions

(C) 2012 ECS - The Electrochemical Society 


\title{
Electrochemical Determination Of The Real Area of Nanocrystalline Boron Doped Diamond
}

\author{
E.Saito, F.A Souza, A.F. Azevedo,N.G. Ferreira, M.R. Baldan \\ Laboratório associado a Sensores, São José dos Campos, 12227-010 , Brasil
}

\begin{abstract}
The present work is devoted to evaluate the area of samples of nanocrystalline Boron Doped Diamond grown with different dopant solutions. The samples were characterized by Scanning Electron Microscopy (SEM) and Atomic Force Micrsocopy (AFM) and electrochemically by Differential-capacitance (MottSchottky plots) and Cyclic Voltammetry. By SEM was possible detect "cauli flower" morphology and by AFM was possible to quantify the roughness of the samples. We evaluate the dopant level by Raman spectroscopy and by Mott Schottky plots. The electrochemical roughness measured by AFM was compared with the roughness determined Cyclic Voltammetry.
\end{abstract}

\section{Introduction}

Boron Doped diamond (BDD) films have expanded, in the last decades, the electrochemical applications as inert electrodes for waste water treatment (1), electrosynthesis(2), environmental sensors (3), etc. Microcrystalline diamond films can be grown over several substrates (4), different donors as nitrogen, sulphur, boron $(7,8,9)$ and by a wide range of dopant concentration(10) however each kind of dopant still presents some challenges to effective control. In the past decade, at Argonne institute, was started the reducing of the grains the hydrogen by inert gas addition as $\mathrm{N}_{2}, \mathrm{He}$, or $\mathrm{Ar}$ at the reactor or by methane increment during the growth stimulates the re nucleation process in a level that the film presents nanocrystalline grains (11). Recently, nanocrystalline films and properties were reviewed by Williams (12). As well presented, the numbers of publications about these films have a relevant increment during the last years. As appointed experimentally by hall measurements, Nanocrystalline films can present new characteristics as the $\pi$ and $\pi^{*}$ states around Fermi energy introduced by $\mathrm{sp}^{2}$ carbon which contributes to charge transport mechanism (11).

The determination of the area of electrodes is an important and polemic subject to treat. As presented by Trassati (13), several methods can be used to give approximate values of the real area but each measurement has some limitations from physical chemical point of view. The dependence of the capacitive current with the sweep rate gives a distinction between the "more exposed" portion of electrode (measured at higher rates) and the total part of electrode obtained at low scar rate. Differently from other methods selected as AFM, the electrochemical determination of the roughness factor reveals regions more accessible than others on electrode surface. 


\section{Experimental}

Nanocrystalline Growing condition

The BDUND films were grown by Hot Filament Chemical Vapor Deposition (HFCVD) on P-type Si (100) substrates with $1 \mathrm{~cm}^{2}$. The substrates were cleaned and treated in ultrasonic bath with hexane with 0.25 diamond particles during 60 minutes. The processes scratch and seed the surfaces to promote growing efficiency of the films. The growing ambient was keep at $900 \mathrm{~K}$ and 6.7 Tor of pressure by the deposition time of 10 hours. The $\mathrm{CH}_{4} / \mathrm{H}_{2}$ ratio was controlled in volumetric $0.05 \%$. Pure Hydrogen was bubbled in a chamber with methane and Boron oxide in a concentration of $1.10^{4} \mathrm{ppm}$ (sample lightly doped) (BDUND1) and $2.10^{4} \mathrm{ppm}$ (heavily doped sample)(BDUND2).

The samples were characterized by Scanning electron Microscopy (SEM) to evaluate the morphology of the films and Atomic Force Microscopy (AFM) was selected to evaluate and quantify the roughness of the samples. The number of donors and the flat band potential were evaluated by "Mott Schottky" plots and the Cyclic Voltammetry technique was selected to evaluate the internal and external capacitance and estimate the electrochemical "roughness factor".

$\underline{\text { Results }}$

$\underline{\text { Scanning electron microscopy }}$

SEM images of the samples were presented at Figure 1. The SEM images did not revealed faceted crystalline diamond with different doping flux. From images is possible to evaluate qualitatively the smoothness and uniformity of the samples. The samples present high uniformity and some local agglomerations. The morphology is explained as a consequence of the secondary nucleation or re-nucleation process in diamond growing. The BDUND film presents lower uniformity and suggests the "ballas like" morphology revealed by others works (12).
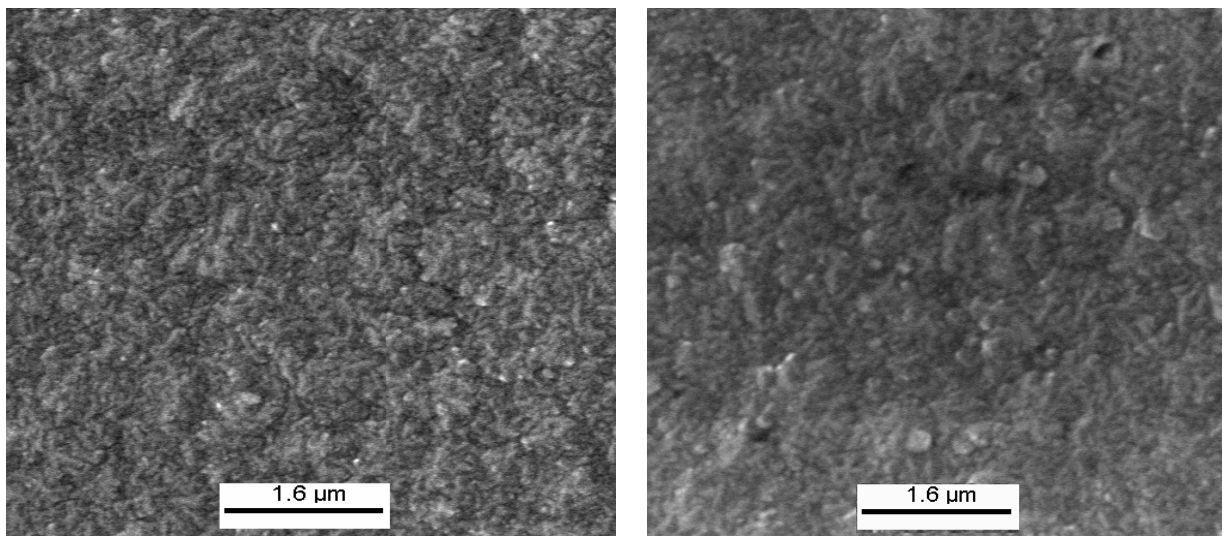

Figure 1 - SEM of the BDUND1 and theBDUND2. 


\section{$\underline{\text { Raman spectroscopy }}$}

The Raman spectra for the samples BDUND1 and BDUND2 are presented in Figure 2. The peak at $1332 \mathrm{~cm}^{-1}$ is corresponding to diamond first order phonon vibration.

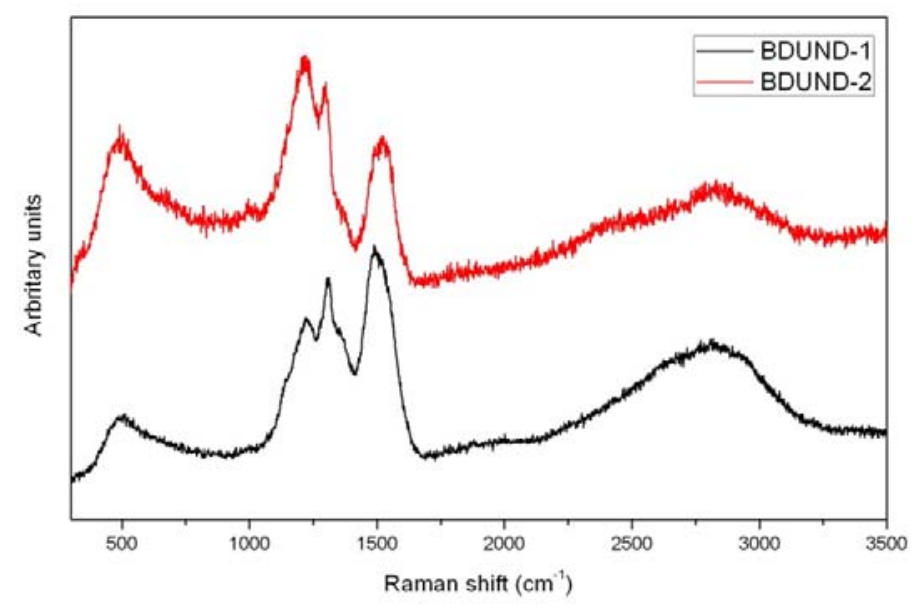

Figure 2 - Raman spectra of BDUND1 and BDUND2.

By using Raman spectroscopy, it was possible to analyze the composition and the quality of the BDD films. At higher $\mathrm{B} / \mathrm{C}$ ratios, the change in the profile of one phonon band becomes progressively pronounced, and at the same time broad bands appears at 500 and $1230 \mathrm{~cm}^{-1}$. The drastic changes in spectrum takes place at higher boron concentration with the asymmetry of one phonon band and the appearance of new broad band centered at $1230 \mathrm{~cm}^{-1}$. The asymmetry of the one phonon band is attributed to the Fano interference between the discrete phonon state and electronic continuum. The Fano line shape is asymmetric with an enhancement of one band of the line with a decrease of a minimum of the other. Pruvost and Deneuville (5) suggested that the Fano effect appears above a critical percolation threshold for the achievement of the metallic conductivity on the boron impurity band while Ager et al. (6) reported that the Fano effect is attributed to the transition from the broadened impurity band to continuum states composed of excited acceptor and valence band sates. In addition, this type of Fano interference in the diamond is quite similar to that for heavily doped silicon that has well discussed in the literature (6).

The presence of a Raman peak at around $1332 \mathrm{~cm}^{-1}$ was verified for the sample BDUND1, which corresponds to the diamond first-order phonon vibration. However, for the sample BDUND2 the intensity of the peak was lower. The emergent band at $1200 \mathrm{~cm}^{-1}$, which is characteristic of the boron doped diamond films, is attributed to the induced disorder in the diamond structure due to the boron incorporation.

These band increases significantly by increasing the doping level which is associated to a drastic reduction in the diamond peak(6). The band at around $1580 \mathrm{~cm}^{-1}$ is attributed to $\mathrm{G}$ band, graphitic phases, and this band is observed in both samples. The presence of a band at around $500 \mathrm{~cm}^{-1}$ is also observed, which is attributed to the vibration of boron pairs in the diamond lattice. By comparing the Raman spectra for the 
two BDD films, the sample BDUND2 showed a higher doping level than the sample BDUND1.
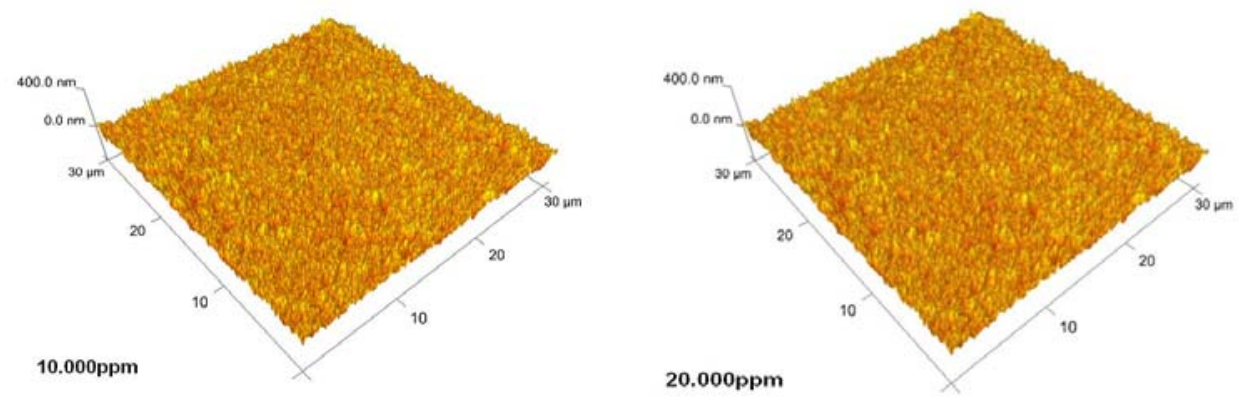

Figure 3 - Atomic Force Microscopy of the samples of BDUND1 and BDUND2.

For the studied samples, by the AFM technique (Fig. 3) was not possible to detect reduction of grain with the increase of the doping level and the evaluation of the area can suggest the same roughness. However, for electrochemical application the roughness is a property that can give the availability of the electrode in face of the electrolytes.

The effective contact between electrolyte and electrode invites the old and important discussion of the real area of electrode, well presented by Trasatti (13). This questionable subject can be evaluated exploring several properties of each material, but each method has some limitation. In this study, to evaluate the real access of the electrolyte to BDUND electrodes, the present study conducted the dependence of the capacitive current relative to scan rate in Cyclic Voltammetry. This linear dependence gives one capacitive current at low scan rates (where the electrolyte have enough time to accommodate to total surface - gives information about the total area - internal and external) and at high scan rate the capacitive current gives information about the external area of the electrode. These approaches have wide uses for oxides (15), giving information about porosity or roughness. For microcrystalline Boron Doped Diamond, Santana et al.(16) performed the study to explore the morphology factor o this kind of material. These authors have alerted the obligation to measure the capacitive current at potentials above the flat band potential and before an anodic treatment $(-3.0 \mathrm{~V}$ in $\mathrm{H}_{2} \mathrm{SO}_{4 \text { (aq.) }}$ for 20 minutes) to eliminate the presence of the non diamond at electrodes surface. Both precautions reduce any resistive current that could interfere in the capacitive response.

It is known that in the interface between electrode and an inert electrolyte, the overall capacitance of the interface is a series of the contribution of the space charge region, the Helmholtz layer and the diffuse layer. On this system the lower value dominates the sum of capacitances. The interface evaluated by differential capacitance measurement gives the information about the space charge region. Specifically, is useful to do a comparative analysis of the doping efficiency revealed by Raman spectroscopy for doped diamond and estimates the concentration of uncompensated carriers( $\mathrm{Na})$ and the flatband potential ( $\mathrm{Vfb}$ ) at BDUND films. 
The differential capacitance voltage measurements was performed to evaluate the doping efficiency promoted by different fluxes and were made using one single sine potential wave with $20 \mathrm{mV}$ peak-to-peak amplitude and with $1 \mathrm{KHz}$.

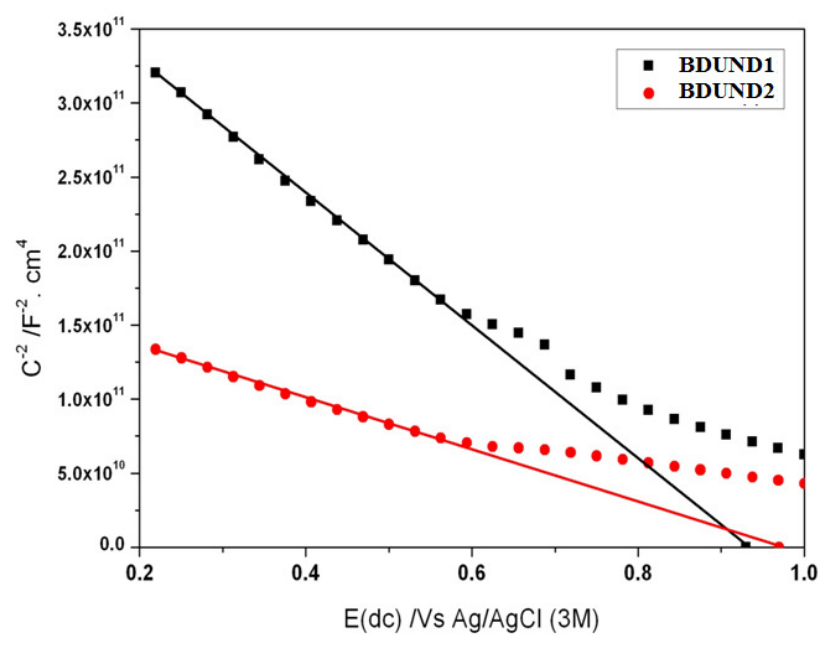

Figure 4 -Mott Schottky plots of the samples of BDUND1 and BDUND2.

The Flat Band Potential was calculated by extrapolation of the function obtained from the linear part of the data. From capacitance voltage measurements is possible determine the flat band potential and calculate the uncompensated carrier concentration (NA).

$$
N_{A}=-\frac{2}{\varepsilon e \varepsilon_{0}\left[\frac{d\left(C^{-2}\right)}{d E}\right]}
$$

Where $\varepsilon$ and $\varepsilon_{0}$ are the relative permittivity of diamond (5.5) and the vacuum permittivity $\left(8,85 \cdot 10^{-14} \mathrm{Fcm}^{2}\right)$, respectively, and e is the electron charge $\left(1,602.10^{-19} \mathrm{C}\right)$.

The fig.5 shows the Mott Schottky plots obtained and the data are presented in table 5 .

Table 5 - Number of acceptors and flat band potential of the samples BDUND1 and BDUND2.

\begin{tabular}{ccc}
\hline Sample & $\mathbf{N a}\left(\mathbf{c m}^{-3}\right)$ & $\mathbf{V}_{\text {fb }}(\mathbf{v s .}$ Ag/AgCl-3M $)$ \\
\hline BDUND1 & $5.71 \times 10^{19}$ & 0.93 \\
BDUND2 & $1.46 \times 10^{20}$ & 0.97 \\
\hline
\end{tabular}

The Data presented at table 1 corroborates the doping efficiency promoted by changing the dopant solution. The more relevant information from these films is the value of the flat band potential since the Voltammetric measurements should be conducted above this value. The measurements of the capacitive current must be conducted at potentials above the flat band potential and without any faradaic current. 
At these potentials, the interface resembles a metal electrolyte interface, since there is a accumulation layer, and excluding any faradaic effects, is possible to minimize interferences to the capacitive current.

As presented earlier (15), the dependence of the capacitive current at electrodes interface in a specific potential (E) can be defined as:

$$
C_{d}=\left(\frac{d i}{d v}\right)_{E}
$$

Where $i$ and $v$ are the current and scan rate.

The low scan rate measurement gives the linear capacitive current which can be correlated to total (internal and external regions of electrodes). The high scan rate response (differential capacity) gives the information about the external region of the electrodes. The differential capacity of the internal region is obtained by subtracting the external differential capacity from the total differential capacity as presented by Eq. 3 .

$$
C_{\text {int. }}=C_{\text {total }}-C_{\text {ext }}
$$

Where $\mathrm{C}_{\text {int. }}, \mathrm{C}_{\text {total }}$ and $\mathrm{C}_{\text {ext. }}$ are the internal, total and external differential capacity. As presented by Trassati (17), the morphology factor $(\varphi)$ can be calculated by the ratio between internal and total capacity as presented by Eq. [4].

$$
\varphi=\frac{C_{\text {int }}}{C_{\text {total }}}
$$

Figures 5 and 6 presents the capacitive current measured for BDUND1 and BDUND2 films and table 2 presents the average roughness $(\mathrm{Ra})$ and the root mean square $(\mathrm{Rq})$ measured by AFM and the internal, external and total differential capacitive and the roughness factor calculated for the samples determined by Voltammetry.

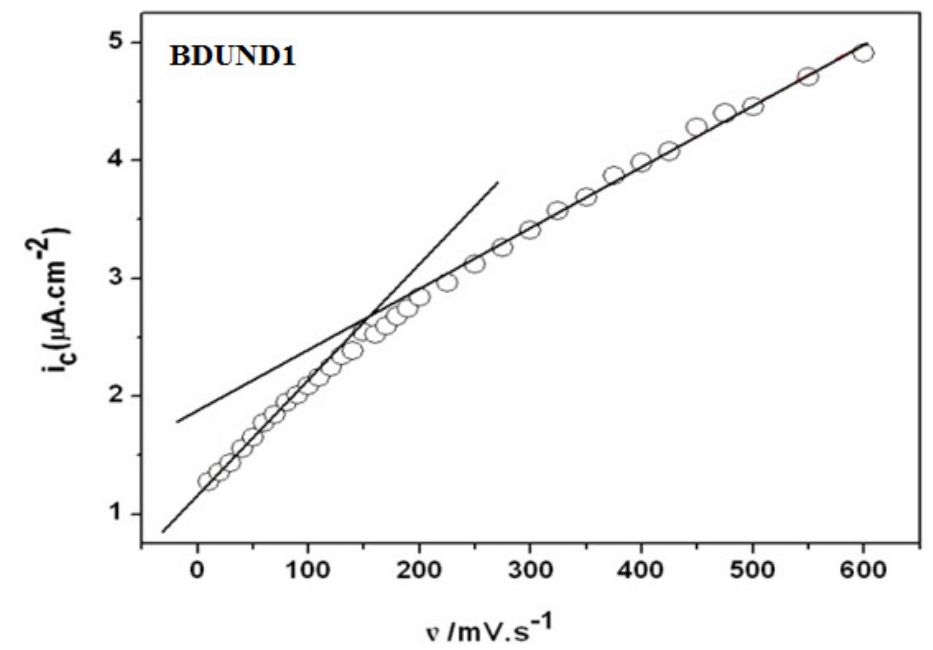

Figure 5 - Dependence of the capacitive current from the samples of BDUND1. 


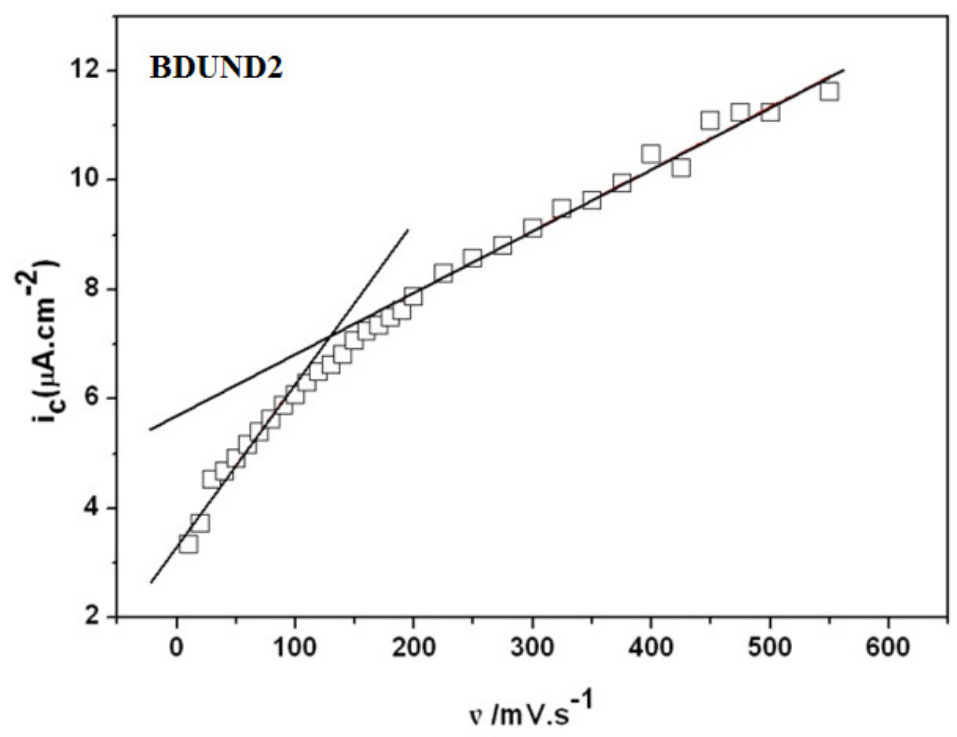

Figure 6 - Dependence of the capacitive current from the samples of BDUND2.

Table 2 - Roughnes of the sample prepared by AFM and electrochemically by Cyclic Voltammetry.

\begin{tabular}{lllllll}
\hline Sample & $\mathbf{R q}(\mathbf{n m})$ & $\mathbf{R a}(\mathbf{n m})$ & $\mathbf{C}_{\mathbf{T}}\left(\boldsymbol{\mu} \mathbf{F} . \mathrm{cm}^{-2}\right)$ & $\mathbf{C}_{\mathbf{e x t}}\left(\boldsymbol{\mu} \mathbf{F} . \mathrm{cm}^{-2}\right)$ & $\mathbf{C}_{\mathbf{i n t}}\left(\boldsymbol{\mu} \mathbf{F} . \mathbf{c m}^{-2}\right)$ & $\boldsymbol{\varphi}$ \\
\hline BDUND1 & 26,4 & 20,7 & 9.82 & 5.33 & 4.48 & 0.45 \\
BDUND2 & 37,3 & 28,3 & 32.24 & 13.14 & 19.1 & 0.59 \\
\hline
\end{tabular}

Besides the difference between the samples, the AFM technique revealed similar values of Ra and Rq. The higher values of BDUND2 can be attributed to higher amount of dopant in reactor favoring the secondary nucleation or re-nucleation process in diamond growing, which reduces the grain size. The values cannot be attributed only to local roughness but to the "ball like" aspect of the morphology suggested by SEM images.

The capacitances values are reduced that found for microcrystalline films by the same technique however stays in accordance with measured by Electrochemical Impedance Spectroscopy for polycrystalline diamond (18). The roughness factor is lower than the appointed for microcrystalline BDD (16) suggesting lower difference between internal and internal regions of the electrodes.

\section{$\underline{\text { Conclusions }}$}

The boron doped diamond revealed morphological similarities from SEM and AFM analysis. The lower capacitive response and the "electrochemical smoothness" appointed by cyclic voltammetry suggest the eligibility of BDUND films for electroanalytical applications. 


\section{Acknowledgments}

The authors are grateful to Brazilian Agencies Capes, CNPq and Fapesp for the financial support, M.L. Brison for the SEM images and Filipe Estevão de Freitas for the AFM images.

\section{References}

1. C. A. Martínez-Huitle,E. Brillas. Angew. Chem. Int., 47, p. 1998 - 2005. (2008)

2. U. Griesbach, D. Zollinger, H. Pütter and C. Comninellis. J. App. Electrochemistry. 35, Number 12, p. 1265-1270 (2005).

3. H.B. Martin, A. Argoitia, U. Landau, A.B. Anderson and J.C. Angus. J. Electrochem. Soc. 143, 6, pp. L133-L136. (1996)

4. B.V. Spitsyn, L.L. Bouilov, B.V.Derjaguin. J. Cryst. Growth. 52, P. 219-226, (1981).

5. F. Pruvost,E. Bustarret, A. Deneuville . Diam. and Relat. Mat. 9, 3-6, P.295299, (2000)

6. J. W. Ager, W. Walukiewicz, M.McCluskey, M.A. Plano, and M.I.Landstrass. Appl. Phys. Lett. 66, 616 (1995).

7. E. B. Lombardi. A.Mainwood, K. Osuch. Phys. Rev. B .70, 205201 (2004).

8. S.C.Eaton, A.B. Anderson, J.C.Angus, Y. E. Evstefeeva, Y.V. Pleskov. Electrochem. Solid-State Lett. 5, (8), pp. G65-G68 (2002).

9. S. Bhattacharyya, O. Auciello, J. Birrell, J. A. Carlisle, L. A. Curtiss, A. N. Goyette, D. M. Gruen, A. R. Krauss, J. Schlueter, A. Sumant, P. Zapol. Appl. Phys. Lett. 79, 1441 (2001);

10. N.G.Ferreira, L.L.G. Silva, E.J. Corat, V.J.Trava-Airoldi, Diam. and Relat. Mat. 11, (8), P. 1523-1531. (2002).

11. P. Achatz, O. A. Williams, P. Bruno, D. M. Gruen, J. A. Garrido; M. Stutzmann. Phys. Rev. B. 74, 1554292006.

12. O.A.Williams. Diam. and Relat. Mat. 20, 5-6, P. 621-640.(2011)

13. S. Trasatti. Pure \& Appl. Chem. 63, (5), 711-734, 1991

14. L.L.G. Silva, M.K. Franco, F. Yokaichiya, N.G. Ferreira, Diam. and Relat. Mat., 11, 153-159 (2002).

15. L.M. Da Silva, L.A. De Faria, J.F.C. Boodts. Electrochim. Acta ,47, 395-403. (2001)

16. M. H.P. Santana, L.A.De Faria, J.F.C. Boodts. Electrochim. Acta ,50, 20172027. (2005)

17. G. Spinolo, S. Ardizzone, S. Trasatti, J. Electroanal. Chem. 423, 49 (1997).

18. Yu V Pleskov. Russ. Chem. Rev. 68 , 381 - 392 (1999) 